\title{
An asymptotic solution for short-time transient heat conduction between two similar contacting bodies
}

\author{
J. R. BARBER \\ Department of Mechanical Engineering and Applied Mechanics, University of Michigan, \\ Ann Arbor, MI 48109-2125, U.S.A.
}

(Received 21 March 1988 and in final form 7 October 1988)

\begin{abstract}
A short-time asymptotic solution is developed for the problem of a half-space, part of the surface of which is raised to a prescribed temperature. A Green's function formulation is used to demonstrate that the heat flux at the surface can be determined from a one-dimensional analysis of the local heat conduction problem, except in the immediate vicinity of the edge of the heated area, where there is a boundary layer, the thickness of which grows with time. This boundary layer is then analyzed in more detail, using Williams' asymptotic technique. In particular, the additional total heat flux to the half-space due to the boundary layer is determined and hence a two-term asymptotic expression for the transient thermal resistance is obtained, which depends only on the area and the perimeter of the heated region. The results are compared with existing solutions for the case of a circular heated area and show good agreement up to Fourier numbers of the order of 0.3. Errors at large times-including the steady state-are still moderate, not exceeding $30 \%$ except for heated areas of large aspect ratio.
\end{abstract}

\section{INTRODUCTION}

THE PROBLEM of heat transfer between two contacting bodies has been a subject of extensive theoretical and experimental study for many years, because of its relevance to the design of heat exchangers and thermal machines. The inevitable roughness of the contacting bodies causes intimate contact to occur only at a numbcr of discretc regions the total area of which is substantially less than the nominal contact area. Most of the heat flux across the interface is constricted to flowing through these 'actual contact areas', thus causing an effective interface resistance, which has been measured experimentally by many authors under steady-state conditions [1-3].

Theoretical estimates of interface resistance $[4,5]$ arc mostly based on a statistical analysis of the distribution of actual contact areas to be anticipated as a function of load and the classical heat conduction solution for the temperature field in two half-spaces in contact over a circular region of their common interface [6].

More recently, interest has been focused on the corresponding transient problem, in which two bodies, initially at different temperatures, make contact for a finite period of time that is insufficient for a steady state to be established [7-10]. This problem finds applications in components of thermal machines making intermittent contact, such as the valves of internal combustion engines [8], and in the heat exchange between impacting particles in a fluidized bed [11, 12]. An important feature of the transient process is that the initial temperature jump at the newly established contact causes an infinite heat flux, which then falls continuously towards the steady state. Thus, the effective instantaneous resistance is initially zero and grows asymptotically towards the steady-state value as time progresses.

The mathematical solution of the corresponding transient heat conduction problem presents challenges not present in the steady-state analysis, particularly at small values of time. Sadhal [10] and Norminton and Blackwell [7] have obtained large-time perturbation solutions for the transient contact of two bodies over a circular region, which appear to give reasonable accuracy when the Fourier number, $F o$, is in the range

$$
F o \equiv \frac{k t}{b^{2}}>1
$$

where $b$ is the radius of the contact area, $t$ the time and $k$ the thermal diffusivity. A corresponding shorttime solution due to Blackwell [13] gives an approximation to the temperature field everywhere except at the edges of the contact area, where the expressions diverge, thus precluding any estimate of total heat flux and hence thermal resistance, which are of course the quantities of most engineering interest.

Schneider et al. [9] have developed a finite difference solution of the problem which agrees with the largetime solutions in $F O>1$, but the results must be rejected at small $\mathrm{Fo}$, since the resistance was found to tend to a finite limit instead of zero, as demanded by simple physical arguments. This is probably a consequence of the finite grid size in the vicinity of the contact area, since at small times the temperature will differ from the initial value only in a very small surface layer under the contact area. 


\section{NOMENCLATURE}

$\begin{array}{ll}A & \text { extent of the contact area } \\ b & \text { radius of the circular contact area } \\ c & \text { specific heat } \\ c_{i} & \text { coefficients of Fourier series } \\ & \text { representation, see equation }(25) \\ C & \text { numerical constant, see equation (31) } \\ F(x, y, t) \quad \text { prescribed surface temperature } \\ F o & \text { Fourier number } \\ G(R, t) & \text { exp }\left(-R^{2}\right) / R t \\ k & \text { thermal diffusivity } \\ K & \text { thermal conductivity } \\ q & \text { heat flux per unit area } \\ Q & \text { total heat flux } \\ \Delta Q & \text { heat flux per unit length due to the } \\ & \text { boundary layer } \\ r^{*} & \text { thickness of boundary layer }\end{array}$

$$
\begin{array}{ll}
R & r / \sqrt{ }(4 k t) \\
S & \text { minimum distance to boundary } \\
S & \text { perimeter of the contact area } \\
T(x, y, t) \quad \text { temperature } \\
T_{0} \quad \text { prescribed uniform temperature in the } \\
& \text { contact area } \\
x, y, z & \text { Cartesian coordinates } \\
r, \theta & \text { polar coordinates. }
\end{array}
$$

Greek symbol$$
\rho \text { density. }
$$

\section{Superscript}

Abel transform, see equations (7) and (8).
In this paper we restrict attention to the problem of contact between half-spaces of similar materials, in which case conditions of symmetry dictate that the contact region(s) adopt a constant uniform temperature equal to the mean of the initial temperatures of the half-spaces. The problem can therefore be reduced to that of a single half-space, initially at zero temperature, part of the boundary of which is raised to a constant uniform temperature at time $t=0$.

We first use a Green's function formulation of the problem which, like Blackwell's solution [13], can be used to develop a formal asymptotic solution for the temperature field, except in the immediate vicinity of the edge of the heated region, where the iterative method diverges. We then concentrate on the local asymptotic field at this edge, where the heat flux first deviates from the initial uniform value. This enables us to obtain a two-term approximation to the total heat flux and hence the effective transient thermal resistance at small values of $t$. Both methods can be applied to problems involving a heated region of arbitrary shape.

\section{GREEN'S FUNCTION FORMULATION}

We consider the problem of the half-space, $z>0$. initially at zero temperature, with the boundary conditions

$$
T(x, y, 0, t)=F(x, y, t) ; \quad x \supset A, \quad t>0
$$

$$
\begin{aligned}
& q_{z}(x, y, 0, t)= \\
&-K \frac{\partial T}{\partial z}(x, y, 0, t)=0 ; \quad x \supset \bar{A}, \quad t>0
\end{aligned}
$$

where $A$ is some region of the surface $z=0, \bar{A}$ comprises all points of the surface not included in $A$ and $F(x, y, t)$ is a prescribed surface temperature. The temperature $T(x, y, z, t)$ is also required to satisfy the heal conduction equation

$$
\nabla^{2} T=\frac{1}{k} \frac{\partial T}{\partial t}
$$

Suitable solutions of equation (4) can be obtained by superposition, using the classical solution for an instantaneous point source of heat (see Section 10.2 in ref. [14]). Thus, if the heat flux, $q_{z}$, in the heated region $A$ is denoted by $q(x, y, t)$, the corresponding surface temperature distribution can be written in the form

$$
\begin{gathered}
F(x, y, t)=\frac{1}{4 \rho c(\pi k)^{3 / 2}} \int_{A} \int_{0}^{t} \frac{q\left(x^{\prime}, y^{\prime}, t^{\prime}\right) \mathrm{e}^{-R^{2}} \mathrm{~d} t^{\prime} \mathrm{d} A}{\left(t-t^{\prime}\right)^{3 / 2}} \\
x \supset A
\end{gathered}
$$

where

$$
R^{2}=\frac{r^{2}}{4 k\left(t-t^{\prime}\right)} ; \quad r^{2}=\left(x-x^{\prime}\right)^{2}+\left(y-y^{\prime}\right)^{2}
$$

Equation (5) is a multiple integral equation which can in principle be solved for the unknown heat flux, $q$, from which the temperature field in the entire halfspace could then be recovered.

A more convenient form of equation (5) can be obtained by taking the Abel transform of each side, defined by the relation

$$
f(t)=\int_{0}^{t} \frac{f(s) \mathrm{d} s}{\sqrt{ }(t-s)}
$$

the inverse of which is (see, e.g. Section 5.7 of ref. [15])

$$
f(s)=\frac{1}{\pi} \frac{\mathrm{d}}{\mathrm{d} s} \int_{0}^{s} \frac{\tilde{f}(t) \mathrm{d} t}{\sqrt{(s-t)}} .
$$


Applying this operation to equation (5) gives

$$
\begin{aligned}
& \tilde{F}(x, y, t)=\frac{1}{4 \rho c(\pi k)^{3 / 2}} \\
& \times \int_{0}^{t} \int_{A} \int_{0} \frac{q\left(x^{\prime}, y^{\prime}, t^{\prime}\right) \mathrm{e}^{-R^{2}} \mathrm{~d} t^{\prime} \mathrm{d} A \mathrm{~d} s}{\left(s-t^{\prime}\right)^{3 / 2}(t-s)^{1 / 2}} ; x \supset A \\
&=\frac{1}{4 \rho c \pi k^{3 / 2}} \int_{0}^{t} \int_{A} \frac{q\left(x^{\prime}, y^{\prime}, t^{\prime}\right) \mathrm{e}^{-R^{2}} \mathrm{~d} A \mathrm{~d} t^{\prime}}{R\left(t-t^{\prime}\right)}
\end{aligned}
$$

on changing the order of integration and performing the inner integral.

Now the function

$$
G\left(R, t-t^{\prime}\right)=\exp \left(-R^{2}\right) / R\left(t-t^{\prime}\right)
$$

behaves like a delta function as $\left(t-t^{\prime}\right) \rightarrow 0$, in the sense that $G(R, 0)=0, r>0$ and

$$
\lim _{t \rightarrow r^{\prime}} \int_{0}^{\infty} G\left(R, t-t^{\prime}\right) 2 \pi r \mathrm{~d} r=4 \pi^{3 / 2} k
$$

Thus, if we differentiate equation (10) with respect to $t$, we obtain

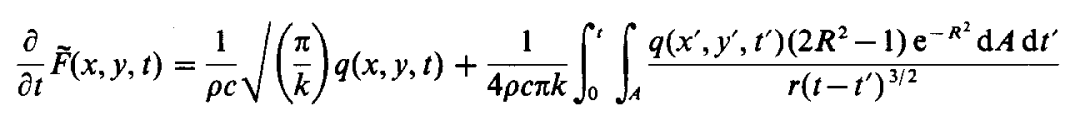

which can be written as a Volterra equation for the unknown function, $q$, in the form

$$
q(x, y, t)=\rho c \sqrt{\left(\frac{k}{\pi}\right)} \frac{\partial}{\partial t} \tilde{F}(x, y, t)-\frac{1}{8 \pi^{3 / 2} K} \int_{0}^{t} \int_{A} \frac{q\left(x^{\prime}, y^{\prime}, t^{\prime}\right)\left(2 R^{2}-1\right) \mathrm{e}^{-R^{2}} \mathrm{~d} A \mathrm{~d} t^{\prime}}{R\left(t-t^{\prime}\right)^{2}} .
$$

The integrand in the last term of equation (13) is only significantly different from zero if $R$ is less than some critical value $R^{*}$, which might be taken to be about 3 for reasonable computational accuracy. Furthermore, when $\left(t-t^{\prime}\right)$ is small, this corresponds to a small range of values of $r\left(<R^{*} \sqrt{ }\left(4 k\left(t-t^{\prime}\right)\right)\right)$. This of course is merely a statement of the physical principle that after a short period of time, a heat input only significantly affects the temperature in a local region. However, it can also be shown that the total value of the integral term is vanishingly small if $q$ is uniform (not necessarily zero) throughout this small region of influence.

It follows that equation (13) can be used to develop a formal asymptotic solution for the heat flux, $q$, at small times, using the conventional iterative solution method for integral equations. The first approximation is obtained by deleting the integral term, after which the current approximation is successively updated by substituting it into the right-hand side of the equation. Convergence is likely to be rapid wherever $q$ is relatively uniform and this condition will be satisfied everywhere except in the immediate vicinity of the edge of the heated region, provided the function $F(x, y, t)$ varies only gradually across the heated area.

We also note that the kernel of the integral term in equation (13) is identically zero when $t^{\prime}=t$ for all $r$. Thus, if we generate a numerical solution by repre-

\section{TEMPERATURE FIELD NEAR THE EDGE}

The iterative solution of equation (13) will not converge in the immediate vicinity of the edge of the heated region and hence this method, like that of Blackwell [13], cannot be used to obtain an approximation to the total heat flux into the body or the transient thermal resistance. To resolve this difficulty. we must investigate in more detail the local thermal field at the edge.

For this purpose, it is convenient to restrict attention to the case where the prescribed temperature $F(x, y, t)$ is a constant $T_{0}$, in which case we conclude from equation (13) that the flux $q$ will be given by

$$
q(x, y, t)=\frac{K T_{0}}{\sqrt{(\pi k t)}}
$$

at all points in the heated region, $A$, the minimum distance of which, $s$, from the edge satisfies

$$
s>r^{*}=R^{*} \sqrt{ }(4 k t)
$$

Equation (15) defines the thickness of a 'boundary layer' adjacent to the edge in which the heat flux differs from the constant value, equation (14). This layer grows inwards with the passage of time. We shall show below (Section 3.2 and Fig. 3) that the thickness of the boundary layer corresponds approximately to the value $R^{*}=1$.

At very small times, when $r^{*}$ is small in comparison 


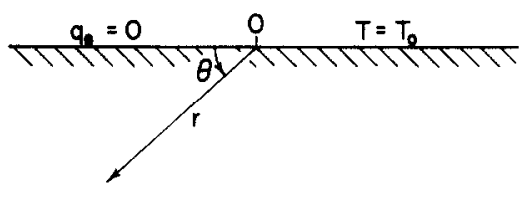

Fig. 2. Section through the boundary layer at BB in Fig. 1, defining the geometry for the asymptotic problem.

with the linear dimensions and the radius of curvature of the boundary of the heated region (see Fig. 1), the local temperature field will be essentially twodimensional and can be determined using the asymptotic method pioneered by Williams [16] in related problems of linear elasticity.

\subsection{Asymptotic analysis}

We consider the two-dimensional problem of the half-plane $r>0,0<\theta<\pi$, with the boundary and initial conditions (see Fig. 2)

$$
\begin{gathered}
T(r, \pi, t)=T_{0} ; \quad t>0 \\
\frac{\partial T}{\partial \theta}(r, 0, t)=0 ; \quad t>0 \\
T(r, \theta, 0)=0 ; \quad 0<\theta<\pi
\end{gathered}
$$

which describes the local behavior in a slice normal to the edge of the heated region such as section BB in Fig. 1. The temperature is also required to satisfy the heat conduction equation (4). We anticipate that the heat flux, $q_{\theta}$, will tend to the value given by equation (14) for $r>r^{*}, \theta=\pi$, but this is not imposed as a boundary condition.

The problem is self-similar and hence the dimensionality can be reduced by defining the new variable

$$
R=\frac{r}{\sqrt{ }(4 k t)}
$$

in which case the boundary conditions become

$$
\begin{aligned}
& T(R, \pi)=T_{0} \\
& \frac{\partial T}{\partial \theta}(R, 0)=0
\end{aligned}
$$

and equation (4) requires

$$
\frac{\partial^{2} T}{\partial R^{2}}+\frac{1}{R} \frac{\partial T}{\partial R}+\frac{1}{R^{2}} \frac{\partial^{2} T}{\partial \theta^{2}}=-2 R \frac{\partial T}{\partial R}
$$

Equation (19) shows that as $t \rightarrow 0, R \rightarrow \infty$ for $r \neq 0$ and hence the initial condition (18) translates into a condition at infinity

$$
T(R, \theta) \rightarrow 0, \quad R \rightarrow \infty .
$$

Solutions of equation (22) which also satisfy equation (21) can be found in the separated variable form

$$
T(R, \theta)=R^{p} \Phi\left(p / 2, p+1 ;-R^{2}\right) \cos (p \theta)
$$

where $\Phi$ is a degenerate (confluent) hypergeometric function (see Section 9.2 of ref. [17]). An alternative method of deriving solution (24) is given by Carslaw and Jaeger (15.11, VIII of ref. [14]).

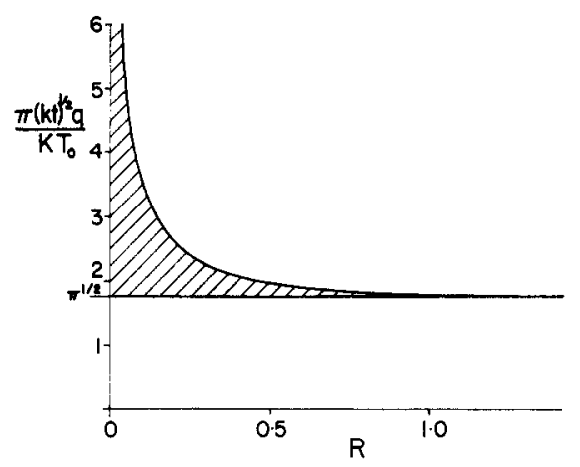

Fig. 3. Heat flux to the half-space in the boundary layer.

Of these expressions, those with $p=(i-1 / 2)$, where $i$ is an integer, give $T=0$ on the boundary $\theta=\pi$, and hence a general solution satisfying boundary conditions (20) and (21) can be constructed in the form

$$
\begin{aligned}
& T(R, \theta)=T_{0}+\sum_{i=1}^{\infty} c_{i} R^{i-1 / 2} \\
& \quad \times \Phi\left(i / 2-1 / 4, i+1 / 2 ;-R^{2}\right) \cos (i-1 / 2) \theta .
\end{aligned}
$$

It remains to determine the coefficients, $c_{i}$, from condition (23). For this purpose, we use the asymptotic form of the hypergeometric functions [17] 9.211.1, to obtain

$$
\begin{aligned}
& T(R, \theta) \rightarrow T_{0} \\
& \quad+\sum_{i=1}^{\infty} c_{i} \frac{\Gamma(i+1 / 2)}{\Gamma(i / 2+3 / 4)} \cos (i-1 / 2) \theta ; \quad R \rightarrow \infty .
\end{aligned}
$$

Thus, on equating (23) and (26), multiplying by $\cos$ $(j-1 / 2) \theta$ and integrating in $0<\theta<\pi$, one obtains

$$
c_{j}=\frac{2 T_{0}}{\pi} \frac{(-1)^{j} \Gamma(i / 2+3 / 4)}{(j-1 / 2) \Gamma(j+1 / 2)} .
$$

\subsection{Heat flux into the half-plane}

We are particularly concerned with the heat flux into the half-plane at the surface $\theta=\pi$, which is given by

$$
\begin{aligned}
q(r, t)= & \frac{K}{r} \frac{\partial T}{\partial \theta}(r, \pi, t) \\
= & \frac{K T_{0}}{\pi \sqrt{ }(k t)} \sum_{j=1}^{\infty} \frac{\Gamma(j / 2+3 / 4)}{\Gamma(j+1 / 2)} R^{j-3 / 2} \\
& \quad \times \Phi\left(j / 2-1 / 4, j+1 / 2 ;-R^{2}\right)
\end{aligned}
$$

from equations (19), (25), and (27). This expression is shown graphically in Fig. 3.

We note that $q$ has a square root singularity at $r \rightarrow 0$, corresponding to the term $j=1$ in equation (29). This is predictable from asymptotic analysis of the corresponding steady-state problem, since a given small value of the dimensionless coordinate, $R$, could correspond either to small $r$ and moderate $t$ or to moderate $r$ and large $t$. As $R \rightarrow \infty, q$ tends to a constant, which can be found by summing the series (28). using the convergent series definition for the 
hypergeometric functions. The value obtained agreed with equation (14) to seven significant digits, thus confirming the numerical accuracy and efficiency of the procedure. We also note that $q$ has essentially converged on this limit at $R=1$, thus justifying the use of $R^{*}=1$ to define the thickness of the boundary layer in equation (15).

The total heat flux into the half-plane is clearly unbounded, but the difference between the total flux and that which would be obtained on the assumption that $q$ is everywhere given by equation (14) is bounded and given by

$$
\begin{aligned}
\Delta Q & =\int_{0}^{\infty}\left[q(r, t)-\frac{K T_{0}}{\sqrt{ }(\pi k t)}\right] \mathrm{d} r \\
& =\frac{2 K T_{0} C}{\pi}
\end{aligned}
$$

where $C$ is a numerical constant corresponding to the shaded area in Fig. 3. This area can be obtained by numerical integration and is found to be 0.785398 , which is equal to $\pi / 4$ to six significant digits. The author believes this agreement to be beyond the bounds of coincidence, but has as yet been unable to obtain an analytical proof, which is therefore left as a challenge to the reader!

\section{APPLICATION TO THREE-DIMENSIONAL PROBLEMS}

The above results can be used to obtain a two-term asymptotic approximation for the local heat flux and the total heat exchange when a region of the boundary is raised to a constant uniform temperature, $T_{0}$, for a short period of time. The local heat flux will be given by equation (14) at all points the minimum distance of which, $s$, from the boundary of the heated area satisfies

$$
s>r^{*}
$$

where $r^{*}$ is given by equation (15). In the boundary layer, $0<s<r^{*}$ the heat flux is given by equation (28), with $R=s / \sqrt{ }(4 k t)$.

The approximation will remain valid as long as the local temperature field in the boundary layer can be taken to be two-dimensional and this in turn requires that the boundary layer thickness be small in comparison with the smallest radius, of curvature, $r_{\min }$ of the heated region, i.e.

$$
t \ll \frac{1}{4 k}\left(\frac{r_{\min }}{R^{*}}\right)^{2} .
$$

This criterion implicitly demands that $A$ should have a smoothly turning boundary, but the error in problems where there are a limited number of corners will probably be moderate as long as

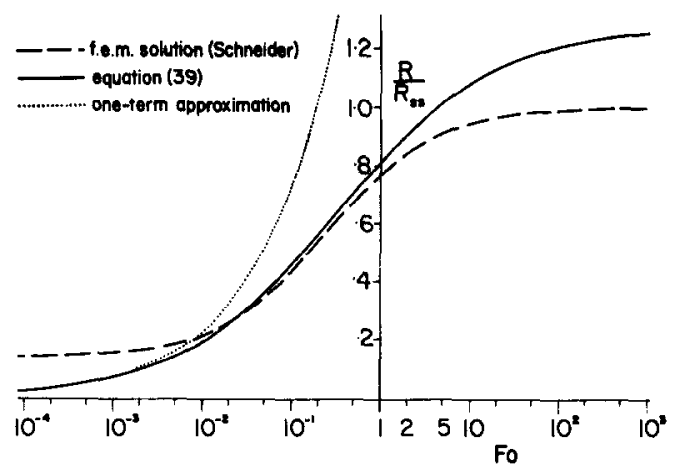

FIG. 4. Comparison of the present solution with the finite element results of Schneider et al. [9] for a circular heated area. The dotted line is obtained if the effect of the boundary layer is neglected.

$$
t \ll \frac{1}{4 k}\left(\frac{d}{R^{*}}\right)^{2}
$$

where $d$ is a representative minimum 'diameter' of $A$.

The total heat flux is then obtained by integrating these expressions over the heated region, $A$. Clearly, the first approximation (14) to the local heat flux gives a term proportional to the total area of the heated region and each element, dS, of the perimeter $S$ contributes a further term proportional to equation (30). Thus, a two-term approximation to the total heat flux is obtained in the form

$$
Q=\left(\frac{K T_{0}}{\sqrt{ }(\pi k t)}\right) A+\left(\frac{K T_{0}}{2}\right) S .
$$

\subsection{Comparison with other solutions}

The only transient three-dimensional thermal contact problem which has received significant attention in the literature concerns the contact of two halfspaces over a circular area of radius $b$. The corresponding steady-state problem has a classical closed form solution [6], in which the total heat flux is

$$
Q=4 K T_{0} b
$$

where $T_{n}$ is now half the difference between the initial temperatures of the half-spaces. We can also define a corresponding steady-state thermal resistance

$$
R_{\mathrm{ss}}=\frac{T_{0}}{Q}=\frac{1}{4 K b} .
$$

Schneider et al. [9] give a finite element solution of the corresponding transient problem and conclude from their numerical results that the transient thermal resistance, $R\left(=T_{0} / Q(t)\right.$, where $Q(t)$ is the instantaneous total heat flux) can be approximated by the expression

$$
\frac{R}{R_{\mathrm{ss}}}=0.43 \tanh [0.37 \ln (4 F o)]+0.57
$$

where $F o$ is given by equation (1). This expression is shown in Fig. 4 in comparison with the result of the 
present analysis, which from equations (35) and (37)

is

$$
\frac{R}{R_{\mathrm{ss}}}=\frac{4}{\pi+\sqrt{(\pi / F o)}} .
$$

The figure also shows the corresponding one-term approximation $R / R_{\mathrm{ss}}=4 \sqrt{ }(\mathrm{Fo} / \pi)$. We note that the addition of the second term in equation (35) extends the useful range of the approximation by two orders of magnitude.

The asymptotic solution agrees closely with Schneider's results in an intermediate range $0.03<$ $F o<0.3$, but diverges both at large and small values of Fo. For $F o<0.03$, the convergence conditions for the present asymptotic solution are clearly abundantly satisfied and hence the difference must be attributed to numerical inaccuracy in Schneider's solution, probably due to inadequate resolution of the finite element grid when the penetration of the thermal disturbance into the half-space is small.

Heasley [18] gave an approximate treatment of the transient problem in which it was assumed that a sphere of material of radius $b$ centered on the contact circle was perfectly conducting. With this approximation, the temperature depends only on the distance from the origin and a solution can be obtained in closed form, giving a resistance equation which is exactly one half of that given by equation (39), for all values of $\mathrm{Fo}$. This difference is attributable to the fact that the area of effective contact between the bodies is increased from the area of a circle $\left(\pi b^{2}\right)$ to the surface area of a hemisphere of the same radius $\left(2 \pi b^{2}\right)$. Thus, Heasley's apparently reasonable approximation leads to very large errors, particularly at small values of time.

\subsection{Behavior at large values of time}

For $F o>0.3$, criteria (33) and (34) are violated and hence the present short-time solution is strictly inapplicable. However, we note that the approximate curve has the correct general shape and even when Fo $\rightarrow \infty$, corrcsponding to the steady-state thermal contact problem, the maximum error never exceeds $28 \%$. Thus the present solution can also be used to obtain a rough estimate of the transient resistance over the whole range of Fourier numbers.

It is interesting to speculate as to whether the approximation would be equally good in large-time problems for other geometries. Various approximate methods have been developed for the corresponding steady-state problem and are discussed and compared in the context of the mathematically analogous elastic indentation problem by Fabrikant [19]. Equation (35) is not the most accurate of these-in view of its derivation as a short-time asymptotic series it would be surprising if it were-but for all the examples discussed by Fabrikant, the error never exceeds $30 \%$, except for long thin contact areas of aspect ratios exceeding 10.

\section{CONCLUSIONS}

The present solution demonstrates that, at small times, the instantaneous contact resistance depends only upon the area and perimeter of the contact region, through the simple relation

$$
R=\left(\frac{K A}{\sqrt{ }(\pi k t)}+\frac{K S}{2}\right)^{-1}
$$

The method can therefore be readily applied to a contact area of any shape.

Reasonable accuracy (better than $1 \%$ ) is maintained up to Fourier numbers of the order of 0.3 , but the error at longer times - even including the steady state $\left(F_{O} \rightarrow \infty\right)$-is still moderate for most geometries.

Acknowledgements-The author is pleased to acknowledge support from the National Science Foundation under contract number MSM-8711557 and from the Aluminum Company of America.

\section{REFERENCES}

1. Yu. P. Shlykov and Ye. A. Ganin, Thermal resistance of metallic contacts, Int. J. Heat Mass Transfer 7, 921929 (1964).

2. A. M. Clausing and B. T. Chao, Thermal contact resistance in a vacuum environment, ASME J. Heat Transfer 87, 243-251 (1965).

3. T. R. Thomas and S. D. Probert, Thermal contact resistance: the directional effect and other problems, Int. J. Heat Mass Transfer 13, 789-807 (1970).

4. M. G. Cooper, B. B. Mikic and M. M. Yovanovich, Thermal contact conductance, Int. J. Heat Mass Transfer 12, 279 (1969).

5. V. S. Novikov, Thermal contact reistance of rough surfaces under compression, Heat Transfer-Sov. Res. 5 , 156-159 (1973).

6. R. Holm, Electrical Contacts Handbook. Springer, Berlin (1958).

7. E. J. Norminton and J. H. Blackwell, Transient heat flow from constant temperature spheroids and the thin circular disk, Q.J. Mech. Appl. Math. 17, 65-72 (1964).

8. J. R. Howard and A. E. Sutton, An analogue study of heat transfer through periodically contacting surfaces, Int. J. Heat Mass Transfer 3, 173-183 (1970).

9. G. E. Schneider, A. B. Strong and M. M. Yovanovich, Transient thermal response of two bodies communicating through a small circular contact area, Int. J. Heat Mass Transfer 20, 301-308 (1977).

10. S. S. Sadhal, Unsteady heat flow between solids with partially contacting interface, $A S M E J$. Heat Transfer 103, 32-35 (1981).

11. J. Sun and M. M. Chen, A theoretical analysis of heat transfer due to particle impact, ASME Paper 86WA/HT-89 (1986).

12. M. Kaviany, Effect of a moving particle on wall heat transfer in a channel flow, Numer. Heat Transfer 13, 111-124 (1988).

13. J. H. Blackwell, Transient heat flow from a thin circular disk-small time solution, J. Aust. Math. Soc. 14, 433442 (1972).

14. H. Carslaw and J. C. Jaeger, The Conduction of Heat in Solids, 2nd Edn. Clarendon Press, Oxford (1959).

15. G. M. L. Gladwell, Contact Problems in the Classical 
Theory of Elasticity. Sijthoff \& Noordhoff, Alphen aan den Rijn (1980).

16. M. L. Williams, Stress singularities from various boundary conditions in angular corners of plates in extension, J. Appl. Mech. 19, 526-528 (1952).

17. I. S. Gradshteyn and I. M. Ryzhik, Tables of Integrals,
Series and Products. Academic Press, New York (1980)

18. J. H. Heasley, Transient heat flow between contacting solids, Int. J. Heat Mass Transfer 8, 147-154 (1965).

19. V. I. Fabrikant, Flat punch of arbitrary shape on an elastic half-space, Int. J. Engng Sci. 24, 1731-1740 (1986).

\title{
UNE SOLUTION ASYMPTOTIQUE POUR LA CONDUCTION BREVE ENTRE DEUX CORPS SEMBLABLES EN CONTACT
}

Résumé-On développe une solution asymptotique brève pour le demi-espace d'un côté de la surface dont la température croît à un niveau prescrit. Une formulation selon Green est utilisée pour montrer que le flux thermique à la surface peut être déterminé à partir d'une analyse unidirectionnelle du problème de conduction thermique, excepté au voisinage immédiat de la surface chauffée, où il existe une couche limite dont l'épaisseur croît avec le temps. Cette couche est étudiée plus en détail en utilisant la technique asymptotique de William. En particulier, le flux de chaleur total additionnel dû à la couche limite est déterminé, et on obtient une expression asymptotique à deux termes pour la résistance thermique variable qui dépend seulement de l'aire et du périmètre de la région chauffée. Les résultats sont comparés aux solutions existantes dans le cas d'une aire chaude circulaire et ils montrent un bon accord pour des nombres de Fourier allant jusqu’à 0,3 environ. Des erreurs pour les grands temps, allant jusqu'au régime permanent, restent modérées et ne dépassent pas $30 \%$ sauf pour des aires chaudes à grand rapport de forme.

\section{EINE ASYMPTOTISCHE LÖSUNG FÜR TRANSIENTE KURZZEITWÄRMELEITUNG ZWISCHEN ZWEI ÄHNLICHEN, IN BERÜHRUNG STEHENDEN KÖRPERN}

Zusammenfassung - Für das Problem einer Halbraumes, bei dem ein Teil der Oberfläche auf eine vorgeschriebene Temperatur gebracht wird, ließ sich eine asymptotische Kurzzeitlösung entwickeln. Mit Hilfe einer Green'schen Funktion wird gezeigt, daß der Wärmestrom an der Oberfläche aus der eindimensionalen Analyse des lokalen Wärmeleitproblems bestimmt werden kann, mit Ausnahme der unmittelbaren Nähe der Ecken der geheizten Fläche, wo eine Grenzschicht existiert, deren Dicke mit der Zeit anwächst. Diese Grenzschicht wird unter Benutzung des asymptotischen Verfahrens nach Williams näher analysiert. Insbesondere wird der Einfluß der Grenzschicht auf den Gesamtwärmestrom hestimmt und daraus ein asymptotischer Ausdruck mit zwei Termen für den transienten Wärmetransport-Widerstand ermittelt, der nur von der Fläche und dem Umfang des geheizten Gebiets abhängt. Die Ergebnisse werden mit vorhandenen Lösungen für den Fall einer kreisrunden beheizten Fläche verglichen und zeigen bis zu FourierZahlen der Größenordnung 0,3 gute Übereinstimmung. Die Fehler für längere Zeiten-einschließlich des stationären Falls-sind erträglich, sie bleiben unterhalb 30\%, mit Ausnahme von geheizten Flächen von großem Seitenverhältnis.

\section{АСИМПТОТИЧЕСКОЕ РЕШЕНИЕ ДЛЯ КОРОТКОВРЕМЕННОЙ ЧАСТИ ПРОЦЕССА НЕСТАЦИОНАРНОЙ ТЕПЛОПРОВОДНОСТИ МЕЖДУ ДВУМЯ ИДЕНТИЧНЫМИ КОНТАКТИРУЮЩИМИ ТЕЛАМИ}

\begin{abstract}
Апотачш-Для хоротких времен получено асимптотическое решение для полупространства, часть поверхности которого поддерживается при заданной температуре. Для определения теплового потока на поверхности при помощи одномерной локальной задачи теплопроводности за исключением окрестности границы нагреваемой области, где находится пограничный слой, толцина хоторого растет со временем, используется метод функции Грина. Затем пограничный слой анализируется более подробно с помощью асимптотического метода Вильямса. В частности, определяется дополнительный общий тепловой поток в полупространство, обусловленный пограничным слоем, и отсюда выводится двухчленное асимптотическое выражение пля нестационарного термического сопротивления, зависящее только от площади и периметра нагреваемой области. Сравнение результатов с имеющимися решениями для случая нагреваемого круга обнарухивает хорошее совпадение с точностью до чисел Фурье порядка 0,3. Погрешности для длительного времени (включая стационарный процесс) тоже умеренны, в пределах 30\%, за исключением нагретых областей с большим отношением сторон.
\end{abstract}

